\title{
"Effectiveness Of Planned Teaching Programme On Knowledge Regarding Postnatal Exercises Among Postnatal Mothers Admitted In Selected Hospitals Of Vadodara."
}

\author{
Ms. Shelin Christie ${ }^{1}$, Ms. Sijo Koshy ${ }^{2}$, Ravindra H.N. ${ }^{3}$, Dr. Rahul Damor ${ }^{4}$ \\ ${ }^{I}$ (Student Final M.Sc. Nursing, Obstetrical and Gynecological Nursing, Sumandeep Nursing College/ \\ Sumandeep Vidyapeeth, INDIA) \\ ${ }_{2}^{2}$ (Assoc. Proff., Obstetrical and Gynecological Nursing, Sumandeep Nursing College/ Sumandeep Vidyapeeth, \\ INDIA) \\ 3 (Principal, Sumandeep Nursing College/ Sumandeep Vidyapeeth, INDIA) \\ ${ }^{4}$ (Assistant Professor, Dept. of Preventive \& Social Medicine, Government Medical College, Surat, INDIA)
}

\begin{abstract}
Postnatal is the period beginning immediately after the birth of a child and extending for about six weeks. Most women are eager to get to some abdominal exercises to firm up their now-stretched-out middles. An evaluative research approach with pre-experimental design was used. The sampling technique used was non - probability convenient sampling. Data was collected from 60 postnatal mothers from selected hospital at Vadodara. The study aims to find out the existing knowledge regarding postnatal exercises among postnatal mothers, to evaluate the effectiveness of planned teaching programme, to find out the association between the post-test scores with their demographical variables. The post test mean knowledge score is significantly greater than the pre-test mean knowledge score. The T calculated value is 32.855 which is more than the tabulated value of at 0.05 level of significance. So we accept $\mathrm{H}_{1}$ and conclude that there is significant difference between pre-test and post- test knowledge score of diabetic patients. There is significant difference in the pre-test knowledge score and post test knowledge score regarding postnatal exercise among postnatal mothers in selected hospital of Vadodara city. The calculated ' $t$ ' value is 32.855 which is much higher than the tabulated ' $t$ ' $=2.00$ at $5 \%$ level of significance. Also the calculated ' $p$ ' value is 0.000 which is ideal for any distribution as compared to acceptable 0.05. this statistically proves the effectiveness of the planned teaching programme in all the areas of postnatal exercise. Thus $H_{I}$ is accepted. The study findings revealed that planned teaching program was highly effective in improving knowledge of postnatal mothers regarding postnatal exercise
\end{abstract}

Keywords: Effectiveness, Knowledge, Planned teaching programme, postnatal mothers, Postnatal Exercise.

\section{INTRODUCTION}

Postnatal is the period beginning immediately after the birth of a child and extending for about six weeks. A more correct term would be postpartum period, as it refers to the mother and less frequently used is Puerperium. Having a baby means making many changes in life, losing sleep, learning how to take care of a tiny person, and dealing with the "new body" that pregnancy caused to have. Most women are eager to get to some abdominal exercises to firm up their now-stretched-out middles. ${ }^{1}$

A number of women experience trouble bringing their abdomen into its original tone and size after childbirth. Some exercise can help our abdomen return to its original size. There has been gradual acceptance that exercise is beneficial during any part of reproductive process. Benefits are particularly apparent for those women exercising postpartum, where exercise have been found to improve cardiovascular fitness, contribute to weight loss, and prevent long term weight retention. ${ }^{2}$

Specific postnatal exercise is fairly important and involves re-strengthening and toning weakened abdomen, lower and upper back muscles and pelvic floor muscles. Postnatal exercise are aimed at strengthening the abdominal muscles, increase the strength of pelvic floor muscles and help you to recover physically and emotionally. A series of physical exercise that are performed by the mother is to bring about optimal functioning of all system and prevent complication. ${ }^{3}$

Exercise after pregnancy helps to return to pre-pregnancy shape and gives increase energy to cope with demands of motherhood. Postpartum exercise appears to be effective in postpartum urinary incontinence. Pelvic floor muscle training appeared to be an effective training in adult women with stress or mixed incontinence. The goal here is to enhance the knowledge regarding postnatal exercise among postnatal mothers. ${ }^{4}$ 


\section{Statement Of The Problem}

"A study to assess the effectiveness of planned teaching programme on knowledge regarding postnatal exercises among postnatal mothers admitted in selected hospitals of Vadodara."

\section{Objectives Of Study}

1. To find out the existing knowledge regarding postnatal exercises among postnatal mothers.

2. To evaluate the effectiveness of planned teaching programme.

3. To find out the association between the post-test scores with their demographical variables.

\section{Hypothesis}

1. $\mathrm{H}_{1}$ : There will be a significant difference in the level of knowledge about postnatal exercises among postnatal mothers.

2. $\mathrm{H}_{2}$ : There will be a significant association of the post test scores and the demographic variables.

\section{Material And Method}

Research design and approach: Pre-experimental one group pre-test post-test design.

Setting: Selected hospitals of Vadodara.

Variables under the study

Independent variables - Planned teaching program

Dependent variables - Knowledge of postnatal mothers

Population: The postnatal mothers who is admitted in the selected hospitals of Vadodara

Sampling techniques: Non probability convenient sampling technique

Sample size: 60 postnatal mothers.

Development of tool for data collection: it consists of 2 parts:-

Part 1:- dealt with the demographic data of the sample

Part 2:- Consisted of multiple choice questions constructed to assess the knowledge of the postnatal mothers regarding postnatal exercise. Total 25 items are included in the questionnaire.

Validity of instrument: To ensure content validity of the tool, the self reportive structured questionnaire is send to 10 experts. The experts are selected based on their clinical expertise, experience and interest in the problem being studied. They are requested to give their opinions on the appropriateness and relevance of the items in the tool. The experts are from the field of nursing. Modifications of items in terms of simplicity and order are made. Reliability: In order to establish the reliability of the tool it is administered to five postnatal mothers. To establish the reliability of the structured interview schedule, split half method is used; Spearman-Brown's Prophecy formula is used for correlation coefficient, which is found to be 0.9 . Thus the tool is found reliable.

Data collection procedure: The data collected from 7 November to 22 November 2013 Sample are selected according to the selection criteria of the study. Consent was obtained from sample. A good rapport is maintained. Self introduction is given by the investigator to the subjects and the purpose of conducting the study is explained.

On the first day, the pre-test data is obtained using the structured questionnaire. On the second day planned teaching programme was given. On the seventh day, post-test is conducted using the same tool to assess the knowledge of patient regarding postnatal exercises.

\section{Analysis of data}

Both descriptive and inferential statistics analyzed on the basis of the objectives and hypotheses of the study. Mean, median, range and standard deviation calculated. ' $t$ ' test is used to assess the effectiveness of Self instructional module on knowledge regarding postnatal exercise among postnatal mothers. The analysis of variance (ANOVA) is used to find out the association between post test knowledge score and selected demographical variables. Data would be presented in the form of tables and graphs. 


\section{Result}

Section 1: Description Of The Sample According To Their Demographic Characteristics.

Section 2: Assessment Of Knowledge Scores Regarding Postnatal Exercise Among Postnatal Exercises

A. Assessment of pre-test knowledge scores regarding postnatal exercise among postnatal mothers in selected hospitals of Vadodara city.

B. Assessment of post-test knowledge scores regarding postnatal exercises among postnatal mothers in selected hospitals of Vadodara city.

\section{Section 3: Testing The Hypothesis - Evaluation Of Effectiveness Of Planned Teaching Program Regarding Postntal Exercise Section 4: Association Of Knowledge Scores With Demographic Variables \\ SECTION 1: Description of sample characteristic}

- Most of the participants i.e. 35\% were in the age group of $18-23$ years, $40 \%$ were in the age group of 24-29 years, and $25 \%$ were in the age group of 30-35 years.

- Among participants $75 \%$ were hindu, $16.7 \%$ were muslims, $5 \%$ were Christian and $3.3 \%$ were Others.

- There were $16.7 \%$ who had no education, $66.7 \%$ who had primary education, $8.3 \%$ had secondary education and $8.3 \%$ were graduates.

- Among the participants $23.3 \%$ were housewives, $33.3 \%$ were self employed, $33.3 \%$ were private employed and $10 \%$ were government employed.

- There were 50\% who resides in urban area, $25 \%$ resides in rural area, about $16.7 \%$ resides in semi rural area.

- Among the participants 55\% hav one children, $28.3 \%$ had two children and $16.6 \%$ had more than two children.

- There were $33.3 \%$ participants who received knowledge from Media like television, radio etc., $23.3 \%$ received information from relatives and friends, 16,7\% received from medical profession and $26.7 \%$ received from printed materials like newspaper magazines etc..

Section 2: Assessment Of Knowledge Scores Regarding Postnatal Exercise Among Postnatal Exercises

\begin{tabular}{|c|c|c|c|c|}
\hline Area & $\begin{array}{c}\text { Maximum } \\
\text { Score }\end{array}$ & Mean & $\begin{array}{c}\text { Standard } \\
\text { Deviation }\end{array}$ & Mean\% \\
\hline $\begin{array}{c}\text { Introduction } \\
\text { On postnatal exercise }\end{array}$ & 5 & 1.12 & 0.940 & 22.332 \\
\hline $\begin{array}{c}\text { Indications and } \\
\text { Contraindication on postnatal exercise }\end{array}$ & 6 & 1.43 & 0.998 & 23.888 \\
\hline General measures & 3 & 0.63 & 0.736 & 21.11 \\
\hline Different types of postnatal exercise & 11 & 2.45 & 1.712 & 22.2727 \\
\hline Total(overall) & 25 & 5.65 & 2.869 & 22.6 \\
\hline
\end{tabular}

Table-2.1: Pre-test knowledge score regarding postnatal exercise.

\begin{tabular}{|c|c|c|c|c|}
\hline Area & $\begin{array}{c}\text { Maximum } \\
\text { score }\end{array}$ & Mean & $\begin{array}{c}\text { Standard } \\
\text { deviation }\end{array}$ & Mean \% \\
\hline Introduction On postnatal exercise & 5 & 4.13 & 0.833 & 82.6 \\
\hline Indications and Contraindication on postnatal exercise & 6 & 5.55 & 1.124 & 92.5 \\
\hline General measures & 3 & 2.48 & 0.651 & 81.666 \\
\hline Different types of postnatal exercise & 11 & 9.3366 & 1.712 & 85.1509 \\
\hline Total & 25 & 21.4966 & 2.598 & 85.4792 \\
\hline
\end{tabular}

Table 2.2: Post-test knowledge score regarding postnatal exercise.

Section 3: Testing The Hypothesis - Evaluation Of Effectiveness Of Planned Teaching Program Regarding Postntal Exercise

\begin{tabular}{|c|c|c|c|c|c|c|c|c|}
\hline \multirow[b]{2}{*}{ Knowledge area } & \multicolumn{3}{|c|}{ Pre test } & \multicolumn{3}{|l|}{ Post test } & \multirow{2}{*}{$\begin{array}{l}\text { t } \\
\text { value }\end{array}$} & \multirow{2}{*}{ p value } \\
\hline & Mean & S.D. & Mean\% & Mean & S.D. & Mean\% & & \\
\hline $\begin{array}{l}\text { Introduction } \\
\text { On postnatal exercise }\end{array}$ & 1.12 & 0.940 & 22.332 & 4.13 & 0.833 & 82.6 & 9.197 & $\begin{array}{l}0.000 \\
S, p<0.05\end{array}$ \\
\hline $\begin{array}{l}\text { Indications and } \\
\text { Contraindication } \\
\text { postnatal exercise }\end{array}$ & 1.43 & 0.998 & 23.888 & 5.55 & 1.124 & 92.5 & 11.128 & $\begin{array}{l}0.000 \\
\mathrm{~S}, \mathrm{p}<0.05\end{array}$ \\
\hline General measures & 0.63 & 0.736 & 21.11 & 2.28 & 0.651 & 81.666 & 6.668 & $\begin{array}{l}0.000 \\
\mathrm{~S}, \mathrm{p}<0.05\end{array}$ \\
\hline $\begin{array}{l}\text { Different types of postnatal } \\
\text { exercise }\end{array}$ & 2.45 & 1.712 & 22.2727 & 9.3366 & 1.712 & 85.1509 & 11.160 & $\begin{array}{l}0.000 \\
S, p<0.05\end{array}$ \\
\hline Total (overall) & 5.65 & 2.869 & 22.6 & 21.4966 & 2.598 & 85.4792 & 15.254 & $\begin{array}{l}0.000 \\
\mathrm{~S}, \mathrm{p}<0.05\end{array}$ \\
\hline
\end{tabular}

Table 3.1: Effectiveness of planned teaching program 


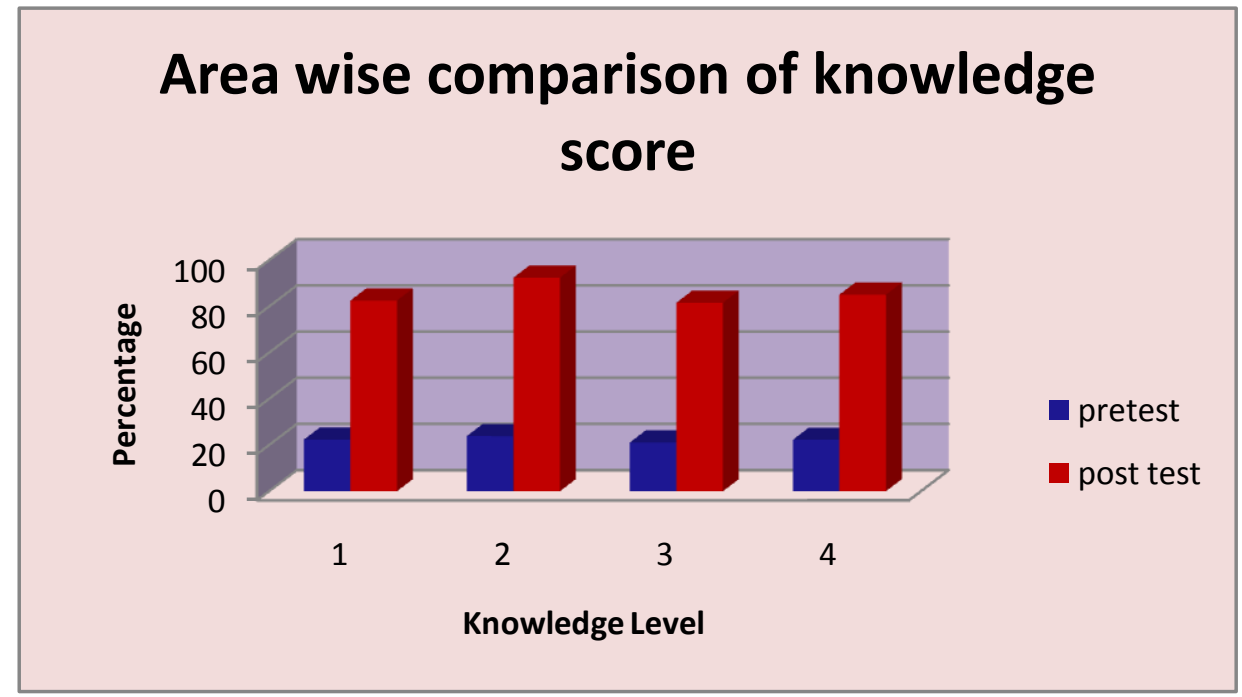

Fig: 1 Bar diagram showing area wise comparison of pre-test and post-test knowledge socres

Table 3.2 Significance difference between overall knowledge score in relation to postnatal exercise among postnatal mothers in selected hospitals of Vadodara city before and after planned teaching.

\begin{tabular}{|l|l|l|l|l|l|l|l|}
\hline Overall & $\begin{array}{l}\text { Maximum } \\
\text { score }\end{array}$ & Mean & $\begin{array}{l}\text { Standard } \\
\text { deviation }\end{array}$ & $\begin{array}{l}\text { Mean } \\
\text { percentage }\end{array}$ & t-value & p-value & Significance \\
\hline Pre-test & 25 & 5.65 & 2.869 & 22.6 & 32.855 & 0.000 & S,p $<0.05$ \\
\hline Post-test & 25 & 21.4966 & 2.598 & 85.4792 & Significnce \\
\hline
\end{tabular}

Section 4: Association Of Knowledge Scores With Demographic Variables

The present study revealed that there is a notsignificant association between pretest knowledge score and Age ( $\mathrm{p}<0.05, \mathrm{~F}=0.236)$, religion ( $\mathrm{p}<0.05, \mathrm{~F}=0.236)$, Type of family $(\mathrm{p}<0.05, \mathrm{~F}=1.053)$, Education $(\mathrm{p}$ $<0.05, \mathrm{~F}=1.053)$, No. of children ( $\mathrm{p}<0.05, \mathrm{~F}=2.535)$, Sources of information $(\mathrm{p}<0.05, \mathrm{~F}=0.334)$, Occupation ( $\mathrm{p}<0.05, \mathrm{~F}=2.441)$, Residence $(\mathrm{p}<0.05, \mathrm{~F}=0.451)$.

\section{Discussion}

The present study has been undertaken to assess the existing knowledge regarding postnatal exercises among postnatal mother in post selected hospitals of Vadodara city , to evaluate the effectiveness of the planned teaching programme and to find the association between the knowledge score and the demographic variables. In this section, the findings of the present study are discussed with reference to the results obtained by the related studies.

The discussion will be made under the following headings.

1. Methodological issues.

2. Findings related to the demographic variables.

3. Findings related to the overall and aspect wise pre test and post test knowledge level of the respondents on ill effects of alcohol.

4. Findings related to the effectiveness of the planned teaching in terms of gain in knowledge score.

5. Findings related to the association of knowledge score with the selected demographic variables.

\section{Conclusion}

The above discussion reveals that the planned teaching programme was effective in improving the knowledge regarding postnatal exercises among the postnatal mother of selected hospital of Vadodara. So the inclusion of this study will help to provide a preventive measure about the postnatal exercises and related complications.

The study shows that there is significant difference in the pre-test knowledge score and post test knowledge score regarding postnatal exercise among postnatal mothers in selected hospital of Vadodara city. The calculated ' $t$ ' value is 32.855 which is much higher than the tabulated ' $t$ ' $=2.00$ at $5 \%$ level of significance. Also the calculated 'p' value is 0.000 which is ideal for any distribution as compared to acceptable 0.05 . This statistically proves the effectiveness of the planned teaching programme in all the areas of postnatal exercise. Thus $\mathrm{H}_{0}$ is rejected. 


\section{Recommendations:}

1. This education should also be given at the time of antenatal period so mother can be learn more with interest.

2. The health professional could arrange weekely educational programme for pre and postnatal mother.

3. Public libraries in the school and college should have resources materials on postnatal exercise.

4. Nurses should update their knowledge constantly and help mother for early healing.

5. College teachers, parents, leaders and health professional should be oriented and sensitized to the topic.

\section{Limitations of the study:}

Health is every one's right and primary prevention is an important aspect in promoting health. In this study postnatal mothers who can read were involve. Generalization would have been if postnatal mothers of selected hospital of Vadodara were included in the study. An increased sample size and duration of the study would allow an evaluation of the effects and duration of the intervention.

\section{Acknowledgement}

I express my gratitude and thanks towards all who have directly or indirectly helped me to complete this study and their support in each major step of the study.

Source of funding: The authors did not receive any financial support from any third party related to the submitted work.

Conflict of interest: The authors had no relationship/condition/circumstances that present a potential conflict of interest.

\section{Ethical Standards}

This study was conducted after getting approval from the Institutional Ethics Committee and after obtaining written consents from all subjects

of teaching program on postnatal exercise. [online series]. www.rguhs.ac.in/cdc/online/cdc/uploads/05-N055144489.doc

[2]. D.C. Dutta, text book of obstetrics, $4^{\text {th }}$ edition, J.P. publications 2004, page no: 610-615.

[3]. J.P. Sharma, guest editorial physiotherapy in obstetrics, the relaxation exercise, Indian Journal 2008.

[4]. Hay Smith J. Et al, Physical therapy or prevention of urinary and fecal incontinence [serialonline]2007http://answersyahoo.com/questionsindia/qid20080930122045AAVR6no 